\title{
Proteomic Analysis of Differentially Expressed Proteins in Bovine Milk During Experimentally Induced Escherichia coli Mastitis
}

\author{
J. L. Boehmer, ${ }^{*}{ }^{1}$ D. D. Bannerman, $\ddagger$ K. Shefcheck, $\S$ and J. L. Ward ${ }^{*}$ \\ *US Food and Drug Administration Center for Veterinary Medicine, Laurel, MD 20708 \\ †Department of Animal and Avian Sciences, University of Maryland College Park, 20742 \\ łBovine Functional Genomics Laboratory, USDA-Agricultural Research Service, Beltsville, MD 20705 \\ §US Food and Drug Administration Center for Food Safety and Applied Nutrition, College Park, MD 20742
}

\begin{abstract}
The objectives of the current study were to profile changes in protein composition using 2-dimensional gel electrophoresis on whey samples from a group of 8 cows before and $18 \mathrm{~h}$ after infection with Escherichia coli and to identify differentially expressed milk proteins by peptide sequencing using matrix-assisted laser desorption/ionization time-of-flight mass spectrometry post source decay. Only proteins present in whey fractions of all 8 cows were sequenced to avoid reporting a protein response unique to only a subset of infected cows. Despite the overwhelming presence of casein and B-lactoglobulin, the low abundance proteins transthyretin, lactadherin, B-2-microglobulin precursor, a-1-acid glycoprotein, and complement C3 precursor could be identified in whey samples from healthy cows. Whey samples at $18 \mathrm{~h}$ postinfection were characterized by an abundance of serum albumin, in spots of varying mass and isoelectric point, as well as increased transthyretin and complement C3 precursor levels. Also detected at $18 \mathrm{~h}$ postinoculation were the antimicrobial peptides cathelicidin, indolicidin, and bactenecin 5 and 7, and the proteins B-fibrinogen, a-2-HS-glycoprotein, S100-A12, and a-1-antiproteinase. Most notable was the detection of the acute phase protein a-1-acid glycoprotein in mastitic whey samples, a result not previously reported. In contrast to methods used in previous proteomic analyses of bovine milk, the methods used in the current study enabled the rapid identification of milk proteins with minimal sample preparation. Use of a larger sample size than previous analyses also allowed for more robust protein identification. Results indicate that examination of the protein profile of whey samples from cows after inoculation with $E$. coli could provide a rapid survey of milk protein modulation during coliform mastitis and aid in the identification of biomarkers of this disease.
\end{abstract}

Received April 24, 2008.

Accepted June 25, 2008.

${ }^{1}$ Corresponding author: jamie.boehmer@fda.hhs.gov
Key words: proteomic analysis, coliform mastitis, milk protein

\section{INTRODUCTION}

For decades, mastitis has been the most costly disease to affect the dairy industry, mainly due to economic losses that stem from decreased milk production, decreased milk quality, discarded milk, cow mortality, and increased cull rates (Schepers and Dijkhuizen, 1991). Cases of mastitis arising from infection by gramnegative bacteria are of particular concern to dairy producers for several reasons: 1) coliform pathogens do not respond well to traditional mastitis treatments including antimicrobial drugs (Shim et al., 2004), 2) a vaccine developed against coliforms has exhibited only limited efficacy (Hogan et al., 1992), and 3) nearly 25\% of the cows suffering from gram-negative mastitis will either die or be culled as a result of systemic complications arising from the host inflammatory response (Eberhart et al., 1987). Because there are a limited number of treatment options available, coliform mastitis and the innate immune response in the bovine mammary gland have been the focus of a considerable amount of research (Hirvonen et al., 1999; Bannerman et al., 2003, 2004). Escherichia coli remains the most prevalent gram-negative bacteria species to cause bovine mastitis, and thus, $E$. coli strains have often been used in research to experimentally induce mastitis (Hirvonen et al., 1999; Bannerman et al., 2004; Lee et al., 2006).

Dramatic changes in milk protein profiles during coliform mastitis occur in response to the release of a toxin from gram-negative bacteria cell walls during bacterial replication or death, known as endotoxin or LPS. Lipopolysaccharide is a proinflammatory molecule that stimulates a rapid inflammatory response in the mammary gland (Shuster et al., 1993; Lee et al., 2003). Epithelial cells in the mammary gland respond to LPS by producing cytokines including IL-8, tumor necrosis factor a (TNFa), and lactoferrin (McClenahan et al., 2005; Pareek et al., 2005), and it has been 
established that IL-18, IL-6, IL-8, and TNFa are all upregulated by LPS (Shuster et al., 1993; Bannerman et al., 2003). The cytokines IL-16, IL-8, and TNFa have also been demonstrated to increase in response to $E$. coli infection in vivo (Bannerman et al., 2004). Interleukin 18 and TNFa are established inducers of fever, the hepatic acute phase response, and the expression of vascular endothelial adhesion molecules, whereas the chemokine IL-8 is known to play a major role in the recruitment of neutrophils from peripheral sites to the mammary gland during mastitis. Cytokine expression after exposure to LPS or E. coli is also thought to cause increased permeability of mammary vasculature, which subsequently results in a dramatic increase in levels of vascular-derived proteins in milk, most notably BSA.

Cytokine expression and the effects of the innate immune response on milk composition during coliform mastitis have been previously characterized; however, changes in actual expression profiles of milk proteins during coliform mastitis are not entirely known. Data reported on cytokine expression after $E$. coli or LPS infection have been based on ELISA, which are limited by antibody availability and reagent development (e.g., generation of recombinant protein to be used as a standard). Proteomic analysis does not rely on antibodies, however, and therefore is not limited to the detection of only a certain number of proteins. Previous attempts to characterize bovine milk proteins using a proteomic approach have been performed on only a small number of cows with mastitis confirmed only by clinical parameters, or have involved the removal of highly abundant proteins before analysis. The desire to better understand underlying changes that occur in the mammary gland in response to invading pathogens, and the need to identify potential targets for new mastitis therapies coupled with advances in proteomic technology have led to investigations into the bovine milk proteome. Comparative analyses of bovine whey have been conducted using 2-dimensional gel electrophoresis (2D-GE) followed by matrix-assisted laser desorption/ionization time-of-flight (MALDI-TOF) mass spectrometry (MS, Yamada et al., 2002; Hogarth et al., 2004; Smolenski et al., 2007). In the previous analyses, high-speed ultracentrifugation was used to produce the whey fraction analyzed (Yamada et al., 2002; Smolenski et al., 2007), and the caseins were removed by either acid precipitation followed by dialysis (Hogarth et al., 2004), or by immunoabsorption (Yamada et al., 2002). All previous analyses were successful in identifying the abundant whey proteins serum albumin, a-casein, B-casein, $\mathrm{k}$-casein, B-lactoglobulin, and a-lactalbumin. Lower abundance proteins, including transthyretin (TTR) and complement C3 a-chain were also identified in whey from 3 healthy midlactation cows (Yamada et al.,
2002), but these analyses did not compare normal and mastitic whey samples and were limited in the number of low-abundance proteins identified despite prior sample clean-up. In comparative proteomic analyses of proteins in normal and mastitic whey, mastitis was established based on clinical parameters (heat in the gland, milk clots, swelling of udder; Hogarth et al., 2004), or the analysis was conducted on samples from only 1 cow with a naturally occurring clinical infection (Smolenski et al., 2007). The more inclusive of the proteomic studies that incorporated both a bottoms-up proteomic approach using 2D-GE followed by MS and a top-down approach using liquid chromatography followed by MS analysis of trypsin-digested skim milk, whey, and milk fat globular membrane fractions succeeded in identifying host defense-related proteins. However, a very small sample size was used $(n=1)$, and either few peptides were sequenced or the proteins were only identified in one of the types of milk fraction analyzed (Smolenski et al., 2007).

The goal of the current study was to utilize samples collected from a larger number of cows $(n=8)$ with experimentally induced coliform mastitis, and to eliminate time-consuming sample clean-up steps such as removal of high-abundance proteins and high-speed ultracentrifugation. Caseins have been the principle target of high-abundance protein removal in sample preparation of milk from healthy cows. Because the removal of caseins requires acid precipitation followed by dialysis to remove acid traces, it is reasonable to theorize that both precipitation and dialysis could result in the loss of other proteins. After pathogen invasion and stimulation of the innate immune response, it has been well established that altered vascular permeability, as a result of local cytokine production, leads to leakage of the serum proteins into milk and the subsequent increase in the milk concentration of BSA. Thus, the primary target of high-abundance protein removal in mastitic whey samples would be BSA. Several of the commercially available serum albumin removal columns contain the nonspecific dye ligand Cibacron Blue F3G-A, which efficiently binds serum albumin, but could also result in the loss of other proteins due to its nonspecificity. It has also recently been demonstrated that several small molecules and proteins bind to serum albumin, and thus, they could be lost as a result of serum albumin removal from samples (Gundry et al., 2007). In addition, other whey proteins including B-lactoglobulin have been shown to participate in the nonspecific binding of other ligands (Konuma et al., 2007), and thus, it is reasonable to speculate that some milk proteins could become bound to a cellular component of the milk. Should a binding event occur, chances of a decrease in abundance or loss of proteins 
Table 1. Proteins identified in normal bovine whey

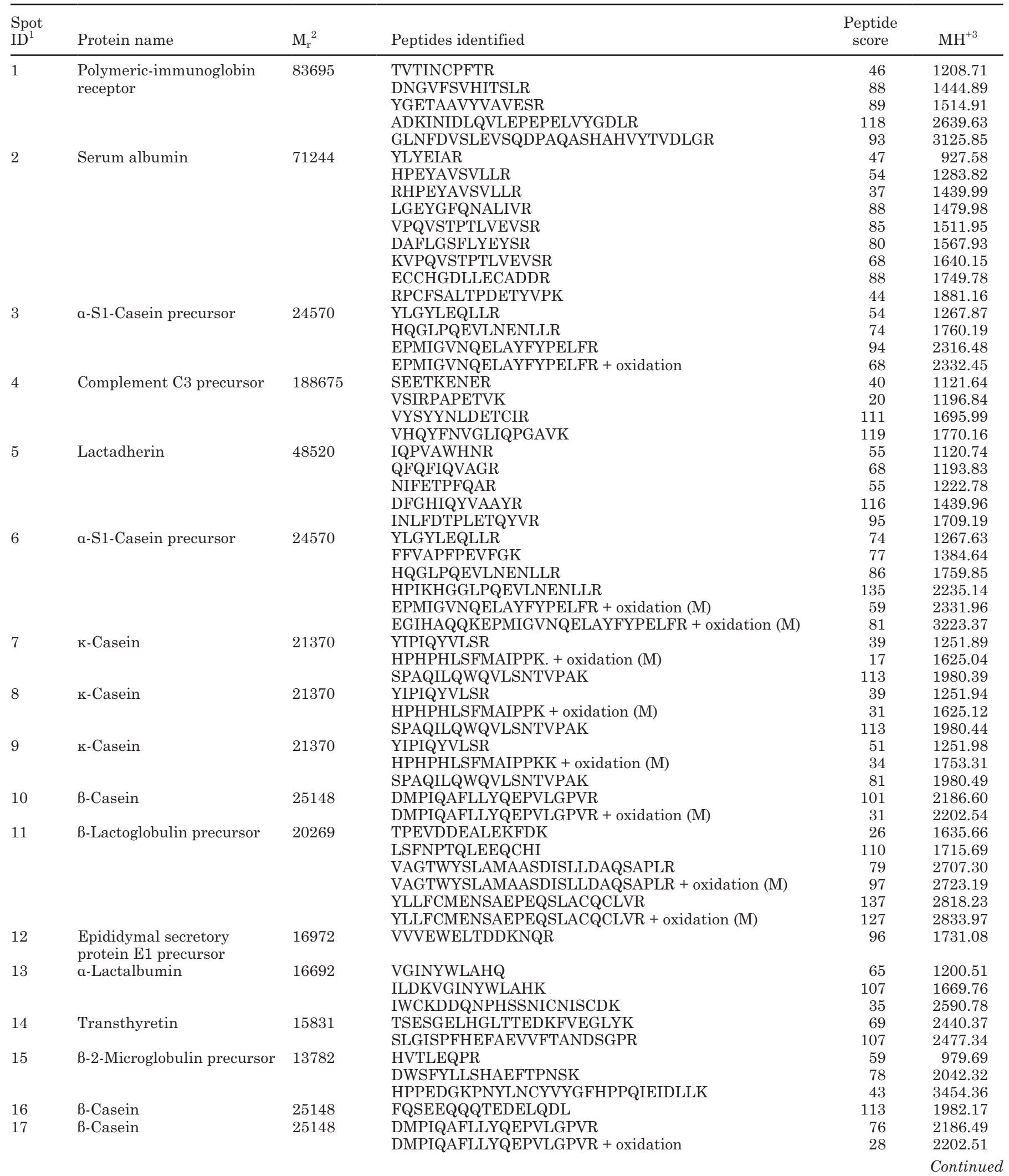


Table 1 (Continued). Proteins identified in normal bovine whey

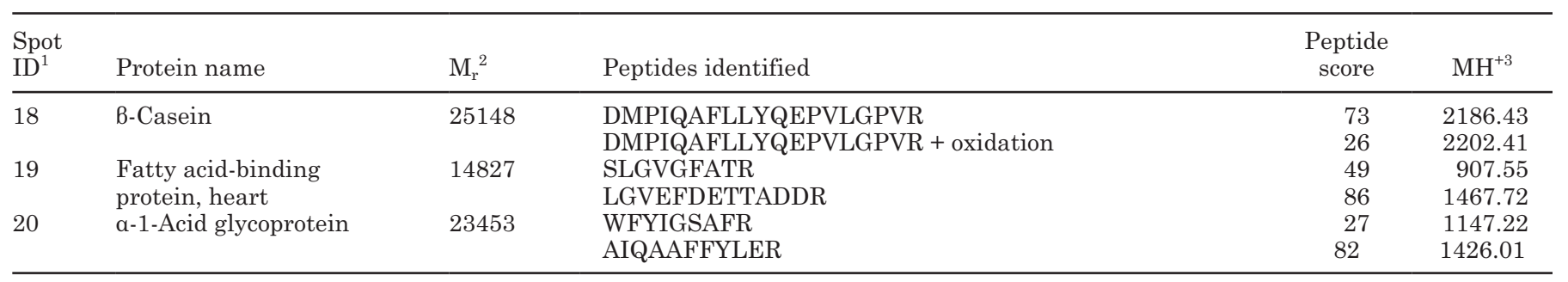

${ }^{1}$ Corresponds to the number assignment in Figure 1.

${ }^{2}$ Average mass of protein (Da).

${ }^{3}$ Mass of charged peptide (Da).

are increased with high-speed ultracentrifugation. The goal of maintaining the large dynamic range of the milk proteins before proteomic analysis by minimizing potential protein losses during sample clean-up steps was to enhance the probability of identifying a greater number of differentially expressed proteins in mastitic versus normal whey samples. The time points chosen for 2D-GE analysis in the study, before (time 0 ) and 18 h after $E$. coli infection, were based on previous reports indicating peak cytokine expression at or around $18 \mathrm{~h}$ after infection with $E$. coli (Bannerman et al., 2004), and preliminary analyses of a full time course (12, $18,24,36$, and $48 \mathrm{~h}$ after infection) that revealed the greatest level of differential protein expression to be at $18 \mathrm{~h}$ after infection with $E$. coli (data not shown). Further knowledge of protein modulation during coliform mastitis could ultimately aid in the identification of biomarkers that could prove useful in evaluating the efficacy of adjunctive therapies in decreasing inflammation associated with clinical mastitis.

\section{MATERIALS AND METHODS}

\section{Milk Samples}

Whey samples that were analyzed in the current study were obtained from an $E$. coli challenge study conducted at the Bovine Functional Genomics Laboratory at the USDA-Agricultural Research Service in Beltsville, Maryland. Briefly, 8 clinically healthy Holstein cows in middle to late lactation were infected in one quarter with E. coli strain P4. Preparation of the inoculum and experimental infection was performed as described previously (Bannerman et al., 2004). Plating of aliquots of the final inoculum on blood agar plates confirmed that cows were infused with $\sim 200 \mathrm{cfu}$ of $E$. coli. For the preparation of whey, milk samples were centrifuged at $44,000 \times \mathrm{g}$ at $4^{\circ} \mathrm{C}$ for $30 \mathrm{~min}$, and the fat layer was removed with a spatula. The skimmed milk was decanted into a clean tube, centrifuged again for $30 \mathrm{~min}$, and the translucent supernatant was collected and stored at $-70^{\circ} \mathrm{C}$. The use and care of all animals in this study were approved by the Animal Care and Use Committee of USDA-Agricultural Research Service Beltsville Agricultural Research Center.

\section{D-GE}

The protein content of the 0 -h (preinfection) and 18-h (postinfection) whey fractions from each cow (n $=8$ ) was determined with a Coomassie binding assay (Coomassie Plus Bradford Assay, Pierce Biotechnology, Rockford, IL) using BSA as a standard. Approximately $200 \mu \mathrm{g}$ of each whey protein sample was diluted in rehydration buffer \{8 $M$ urea, 2\% 3-[(3-cholamidopropyl)dimethylammonio]-1-propanesulfonate, $50 \mathrm{mM}$ dithiothreitol, $0.2 \%$ BioLyte 3/10 ampholyte, 0.001\% Bromophenol Blue; Bio-Rad Laboratories, Hercules, $\mathrm{CA}$ \} to a final sample volume of $200 \mu \mathrm{L}$. After dilution in rehydration buffer, samples were applied to $11-\mathrm{cm}$ $\mathrm{pH}$ 3-10 nonlinear immobilized $\mathrm{pH}$ gradient (IPG) strips (Bio-Rad Laboratories) and focused in a Bio-Rad Protean IEF Cell for $20 \mathrm{~h}$ using the following voltage intervals: $500 \mathrm{~V}$ for $1 \mathrm{~h}, 1,000 \mathrm{~V}$ for $1 \mathrm{~h}, 2,000 \mathrm{~V}$ for 2 $\mathrm{h}, 4,000 \mathrm{~V}$ for $4 \mathrm{~h}$, and $8,000 \mathrm{~V}$ for $12 \mathrm{~h}$. After focusing, IPG strips were equilibrated in buffer I, which consisted of $6 \mathrm{M}$ urea, $2 \% \mathrm{SDS}, 0.375 \mathrm{M}$ Tris- $\mathrm{HCl} \mathrm{pH}$ $8.8,20 \%$ glycerol, and $2 \% \mathrm{wt} / \mathrm{vol}$ dithiothreitol (Bio-Rad Laboratories), at room temperature for $30 \mathrm{~min}$, then alkylated in buffer II, which consisted of $6 M$ urea, $2 \%$ SDS, $0.375 M$ Tris- $\mathrm{HCl} \mathrm{pH} 8.8,20 \%$ glycerol, and $2.5 \%$ $\mathrm{wt} / \mathrm{vol}$ iodoacetamide (Bio-Rad Laboratories), at room temperature for $30 \mathrm{~min}$. The IPG strips were run in the second dimension on 10 to $20 \%$ Tris-HCl polyacrylamide gels (Bio-Rad Laboratories) in 1X Tris-glycine-SDS buffer at $200 \mathrm{~V}$ for $1 \mathrm{~h}$. Gels were fixed in $40 \% \mathrm{MeOH}$ $10 \%$ acetic acid for $1 \mathrm{~h}$ and then stained overnight in SYPRO Ruby stain (Lonza, Walkersville, MD). Gels were destained twice in $10 \% \mathrm{MeOH}-7 \%$ acetic acid for 1 $\mathrm{h}$ at room temperature and then imaged on a Typhoon 8600 multimode image scanner (GE Healthcare BioSciences, Piscataway, NJ). All samples were prepared 
Table 2. Proteins identified in mastitic milk samples $18 \mathrm{~h}$ postinoculation

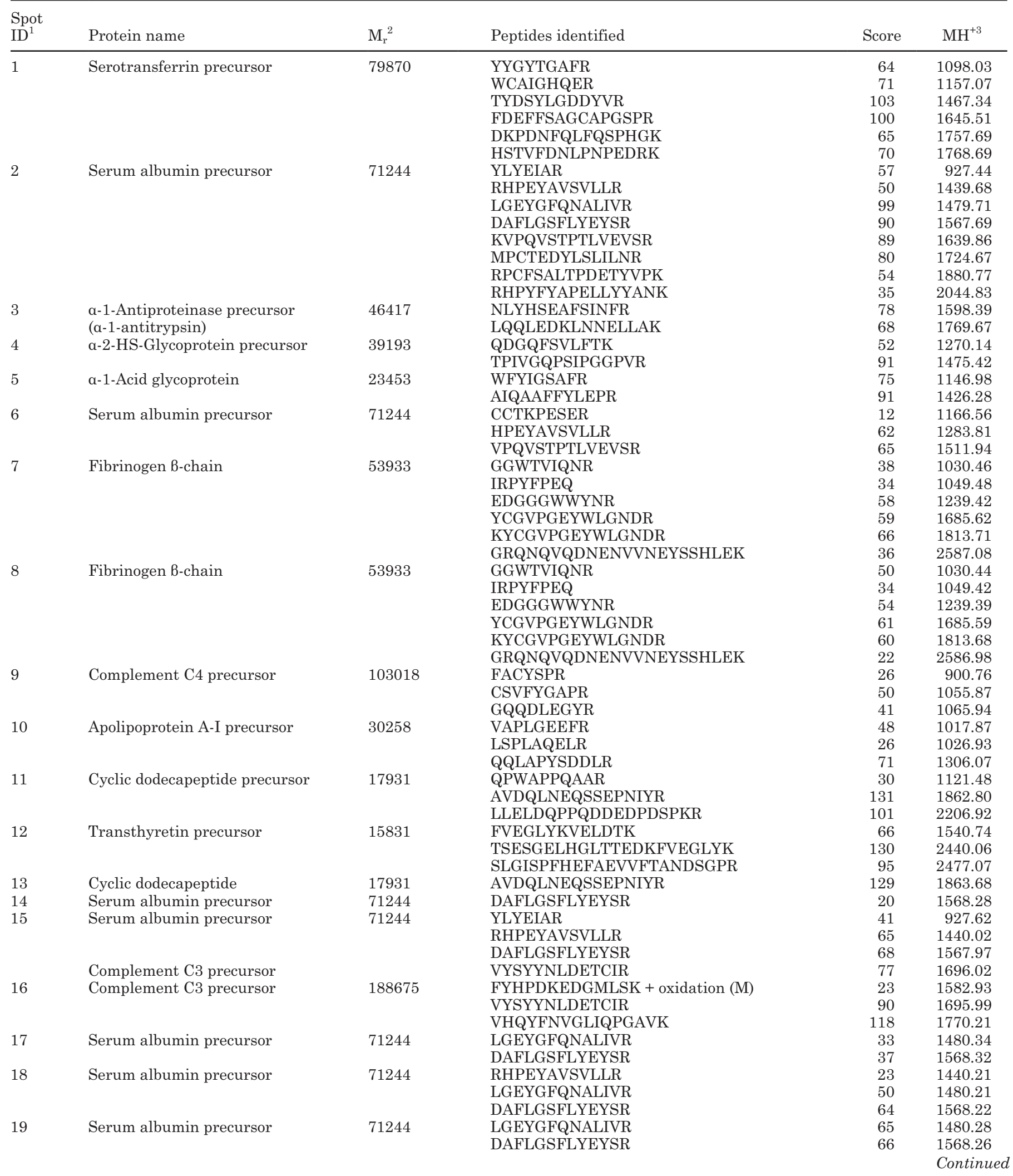


Table 2 (Continued). Proteins identified in mastitic milk samples $18 \mathrm{~h}$ postinoculation

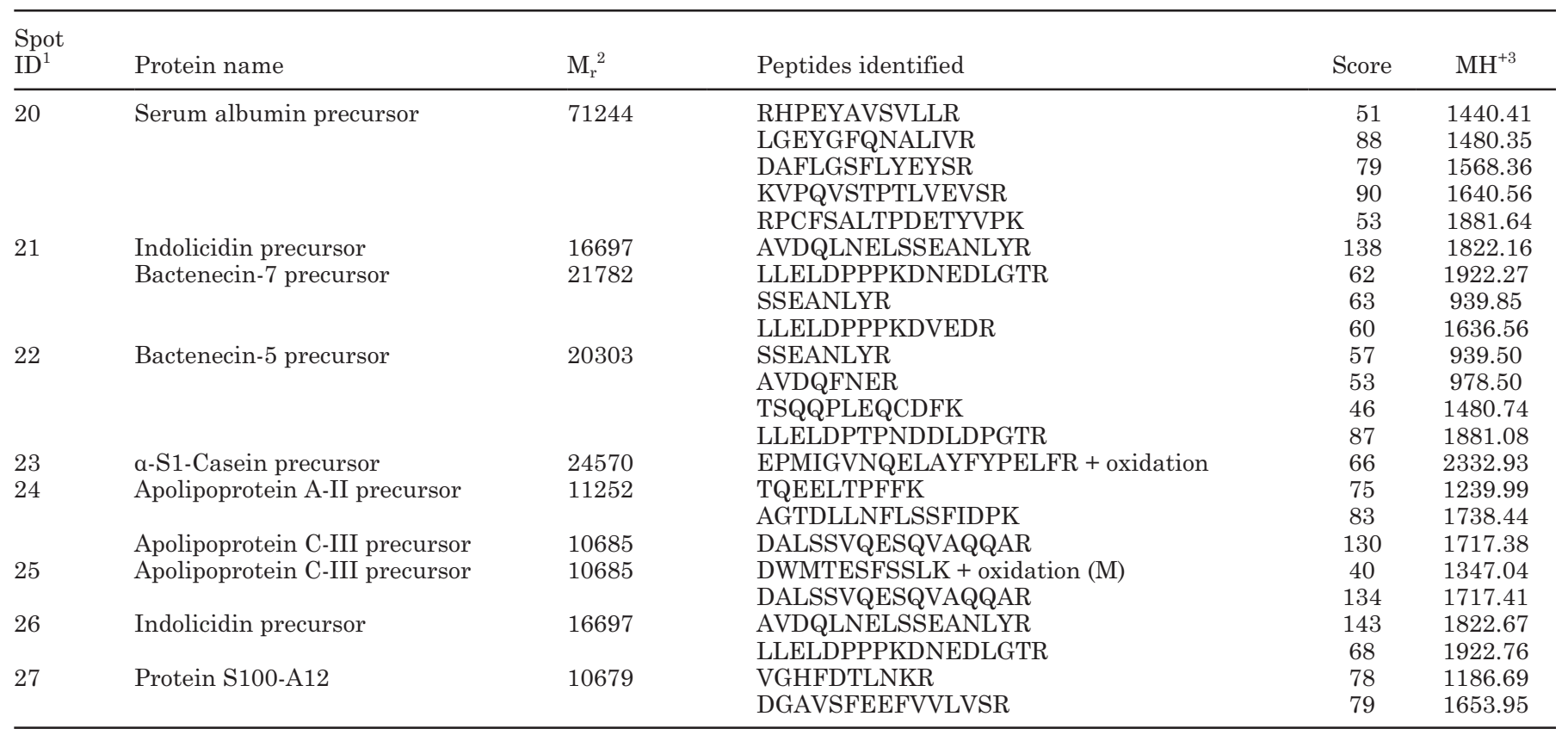

${ }^{1}$ Corresponds to the number assignment in Figure 2.

${ }^{2}$ Average mass of protein (Da).

${ }^{3}$ Mass of charged peptide (Da).

in duplicate for a total of 2 gels per cow for both normal whey and mastitic whey.

\section{Tryptic Digestion}

Protein spots of interest were excised from the gel with a sterile $1,000-\mu \mathrm{L}$ pipette tip or a sterile stainless scalpel blade. Only spots present in all gels from all cows for each time point were excised for identification. Identical spots from replicate gels were pooled and destained at room temperature for $1 \mathrm{~h}$ in $25 \mathrm{~m} M$ ammonium bicarbonate-50\% acetonitrile. Gel spots were dehydrated in 100\% acetonitrile for $5 \mathrm{~min}$ at room temperature and then dried to completeness in a vacuum centrifuge for $20 \mathrm{~min}$ at $22^{\circ} \mathrm{C}$. Spots were rehydrated in $15 \mathrm{\mu g} / \mathrm{mL}$ of trypsin (Sigma-Aldrich, St. Louis, MO) in $25 \mathrm{~m} M$ ammonium bicarbonate and allowed to digest for $16 \mathrm{~h}$ at $37^{\circ} \mathrm{C}$. After digestion, peptides were extracted with $50 \%$ acetonitrile- $5 \%$ trifluoroacetic acid at room temperature for $1 \mathrm{~h}$. Peptides were concentrated in a vacuum centrifuge for $20 \mathrm{~min}$ at $22^{\circ} \mathrm{C}$.

\section{MALDI-TOF MS and MALDI-TOF-TOF Post Source Decay}

Matrix-assisted laser desorption/ionization timeof-flight MS was used to analyze tryptic peptides of digested proteins, and MALDI-TOF-TOF post source decay (PSD) was used for peptide sequencing. Before analysis, $2 \mu \mathrm{L}$ of digested sample was mixed with $2 \mu \mathrm{L}$ of a $5 \mathrm{mg} / \mathrm{mL}$ a-cyano-4-hydroxycinnamic acid (SigmaAldrich) solution prepared in $70 \%$ acetonitrile- $0.1 \%$ trifluoroacetic acid. One microliter of the 1:1 sample:matrix mixture was spotted in triplicate onto a stainless steel MALDI plate and allowed to air dry. Mass spectra were acquired on a 4800 Plus MALDI TOF-TOF Analyzer (Applied Biosystems, Foster City, CA) in positive reflectron mode. A mass range of 900 to 4,000 Da was used for MS analysis, and a total of 100 shots were collected per spectrum at a laser intensity of 4,100. The 6 most intense ions per spectrum exhibiting a minimum signal to noise ratio of 10:1 were automatically selected for MS-MS PSD analyses. A laser intensity of 4,450 was used for PSD analyses, and 100 shots were collected per spectrum.

\section{Protein Identification}

The MALDI-TOF-TOF PSD spectra were searched against the "other mammalian" taxonomy of the Swiss Prot database using Mascot Daemon (Matrix Science, Boston, MA). The enzyme used was set to trypsin, maximum number of missed cleavages allowed was 1 , and the peptide mass tolerance was set at $0.5 \mathrm{Da}$. The fixed and variable modifications were carbamidomethyl and oxidation (methionine), respectively. Protein identities 


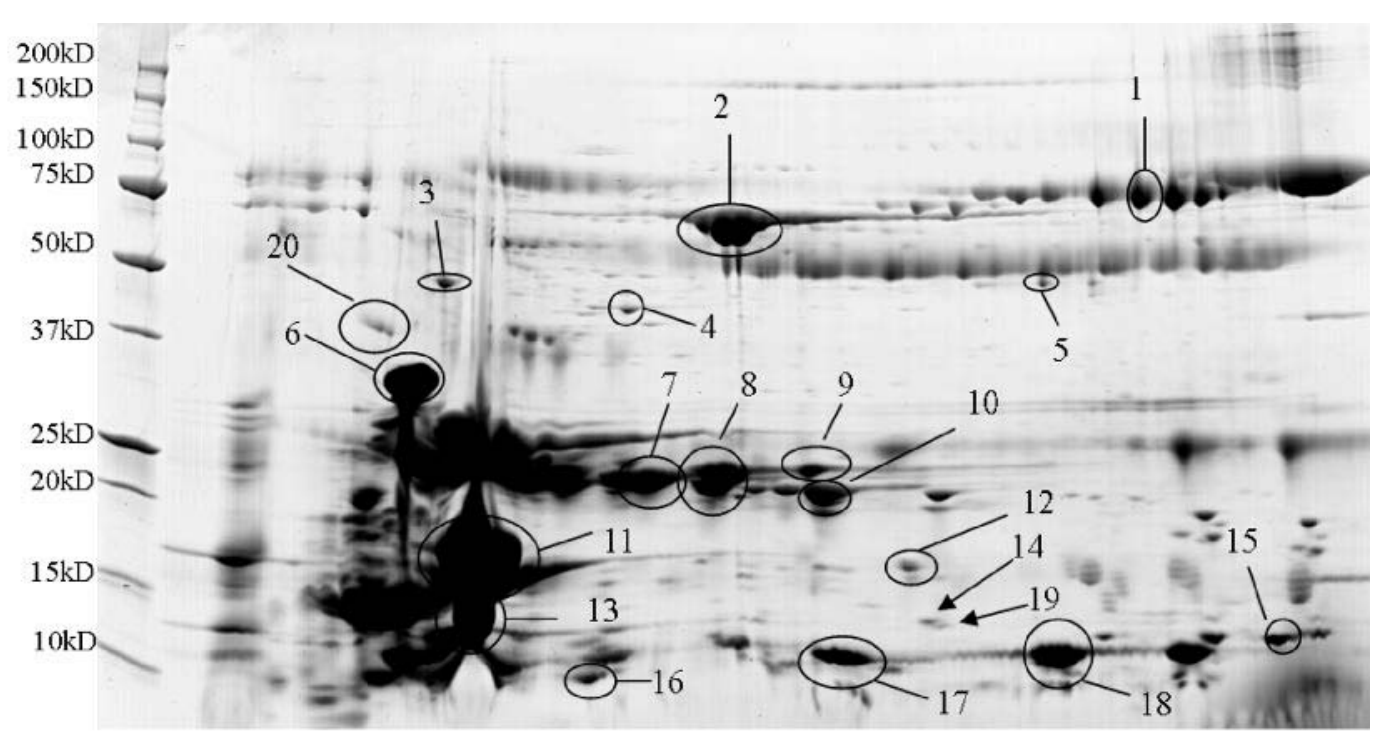

Figure 1. Two-dimensional gel electrophoresis SYPRO Ruby-stained gel (Lonza, Walkersville, MD) of normal bovine whey separated on an 11-cm pH3-10 nonlinear immobilized pH gradient strip and 10 to $20 \%$ Tris-HCl SDS-PAGE. Spot numbers correspond to spot ID in Table

reported by Mascot were individually inspected and matched to protein spots on the gels by comparing the precursor mass list for each spot recorded for each run on the instrument software with the charge-to-mass ratio $(\boldsymbol{m} / \boldsymbol{z})$ of sequenced peptides on the Mascot search results report. Unless noted, only proteins with a minimum of 2 unique peptides sequenced with Mascot identity scores greater than 30 were reported.

\section{RESULTS}

\section{Infection with E. coli Results in Differential Expression of Several Milk Proteins}

Whey from normal bovine milk samples (collected before infection with $E$. coli) and the whey fraction from mastitic milk samples (collected $18 \mathrm{~h}$ after infection with $E$. coli) were separated by $2 \mathrm{D}-\mathrm{GE}$ and identified by peptide sequencing using MALDI-TOF-TOF PSD. Variation in the protein profiles between cows was minimal, and thus, representative gels from both normal and mastitic whey were chosen to illustrate the protein profiles generated in the current study. Only protein spots clearly detected in all gels run on samples collected before or after infection from all 8 cows were selected for follow-up identification. Proteins were identified in whey samples from healthy cows (Table 1) and in mastitic whey samples (Table 2) by the sequencing of at least 2 peptides, with the exception of 2 proteins that had only 1 peptide sequenced.

Normal bovine whey 2D-GE profiles (Figure 1) exhibited an abundance of casein proteins, including
a-S1-casein, B-casein, and $\mathrm{k}$-casein variants, and the whey proteins serum albumin, B-lactoglobulin, and a-lactalbumin. Also identified in whey from healthy cows were polymeric-immunoglobin receptor and several low-abundance proteins including a-1-acid glycoprotein, TTR, complement C3, epididymal secretory protein E1, lactadherin, fatty acid-binding protein (FABP, heart), and B-2 microglobulin.

In contrast, 2D-GE performed on mastitic bovine whey samples (Figure 2A) revealed decreased abundance of a-S1-casein and B-casein and the whey proteins B-lactoglobulin and a-lactalbumin (Figure 3) but a profound increase in bovine serum albumin. $\mathrm{K}$-Casein variants were still evident in the mastitic whey but in decreased amounts. Interestingly, spot 10 on the 2D gels of mastitic whey appeared to be similar to spot 8 on the $2 \mathrm{D}$ gels of normal whey, but the peptides sequenced from spot 10 were from apolipoprotein A-I. Other highly abundant proteins found in mastitic whey included serotransferrin, fetuin (a-2-HS-glycoprotein), fibrinogen, and a-1-acid glycoprotein. Low-abundance proteins identified in mastitic whey included $a-1$ antiproteinase, complement $\mathrm{C} 3$ and $\mathrm{C} 4$, TTR, protein S100-A12, and several antimicrobial peptides (AMP) in the cathelicidin family including cyclic dodecapeptide (cathelicidin-1), indolicidin (cathelicidin-4), bactenecin-5 (cathelicidin-2), and bactenecin-7(cathelicidin-3), as well as apolipoproteins A-I, A-II, and C-III (Figure 2B). Levels of a-1-acid glycoprotein, TTR, and complement C3 levels appeared to increase in comparison to levels in normal whey, but no absolute quantitation 

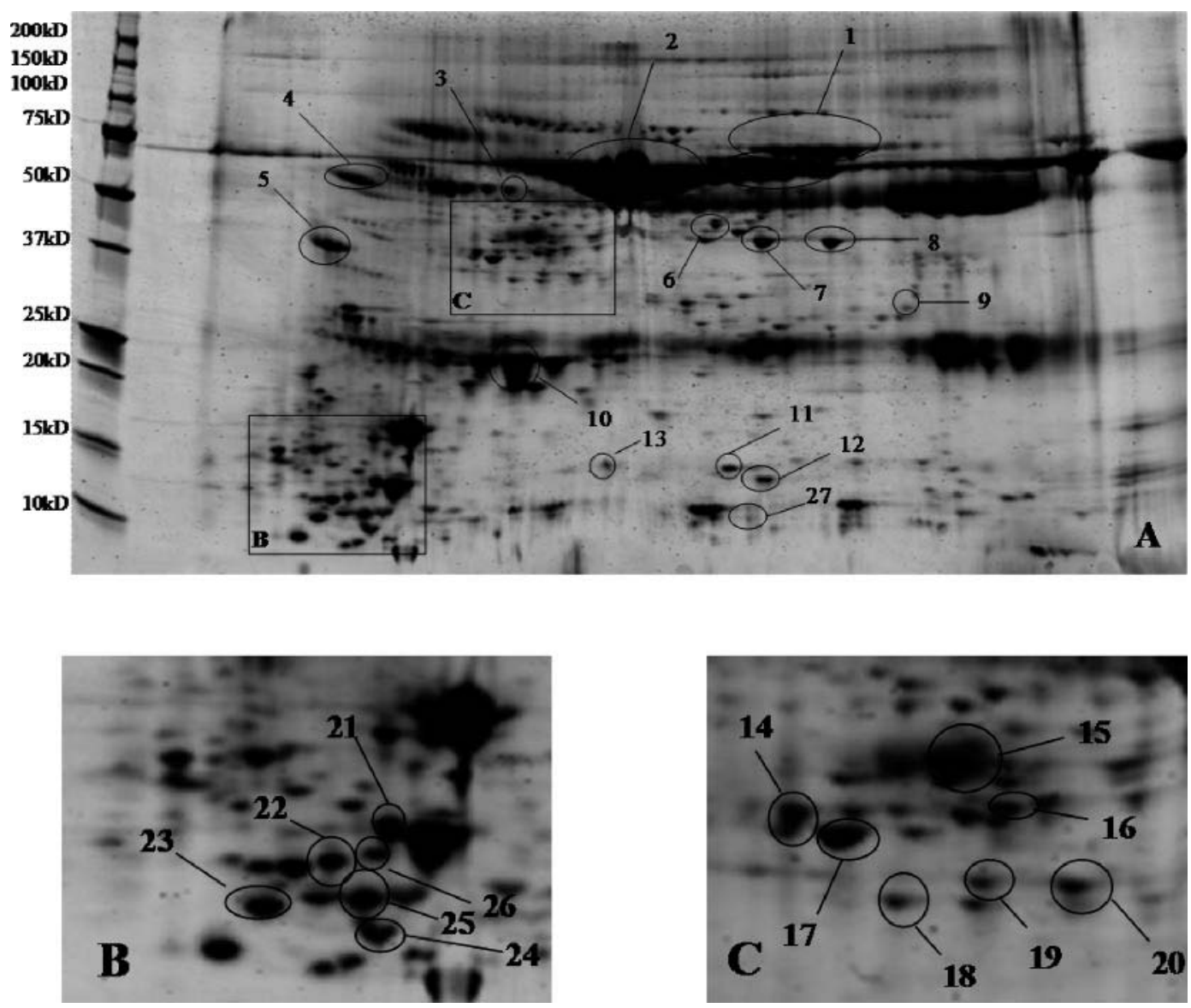

Figure 2. A) Two-dimensional gel electrophoresis SYPRO Ruby-stained gel (Lonza, Walkersville, MD) of mastitic bovine whey separated on an 11-cm pH3-10 nonlinear immobilized pH gradient strip and 10 to 20\% Tris-HCl SDS-PAGE. B) 2D-GE of antimicrobial peptides and apolipoproteins. C) Two-dimensional gel electrophoresis of variant forms of bovine serum albumin. Spot numbers correspond to spot ID in Table 2.

was performed. Other proteins including calbindin, acetylcholine receptor subunits $B$ and $\delta$, matrix metalloproteinase-20, apolipoprotein A-IV, insulin-like peptide, lactotransferrin, and Toll-like receptor 2 proteins were identified (data not shown) in normal and mastitic whey, but too few peptides were sequenced, and the Mascot identity scores were low.

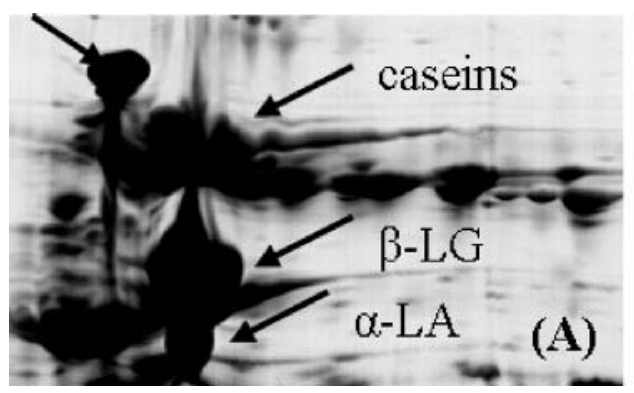

\section{Serum Albumin is Present in Multiple Spots in Mastitic Whey Profiles}

Two-dimensional gel electrophoresis performed on whey samples collected $18 \mathrm{~h}$ after infection with $E$. coli revealed a marked increase in abundance of serum albumin. In addition to intact serum albumin, how-

Figure 3. Comparison of abundance levels of caseins, B-lactoglobulin, and a-lactalbumin in (A) normal and (B) mastitic milk. Arrows indicate caseins, which include $\alpha-S 1, B$, and $\mathrm{k}$, and B-lactoglobulin (B-LG) and $\alpha$-lactalbumin ( $\alpha-\mathrm{LA})$. 

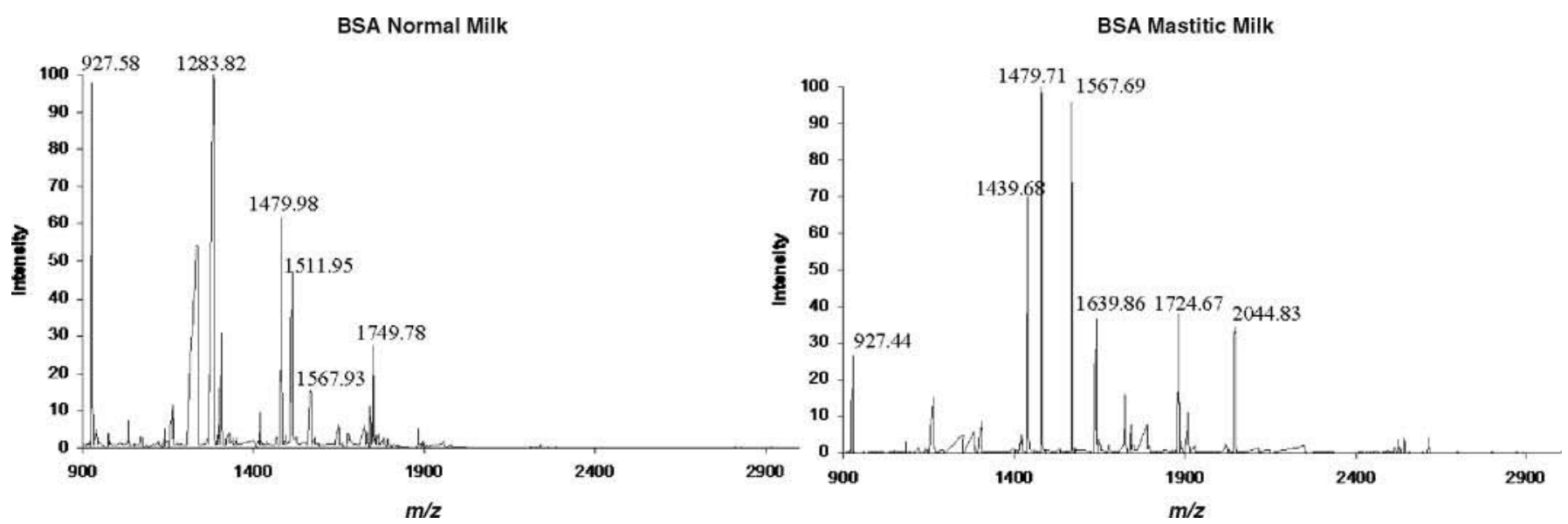

Figure 4. Comparison of mass spectra of the tryptic peptides generated from serum albumin in normal milk and in mastitic milk samples. Normal milk serum albumin tryptic peptides differ slightly in mass and in intensity from serum albumin peptides in mastitic milk.

ever, several smaller forms of BSA with varying mass and isoelectric points were present in mastitic whey samples (Figure 2C). The MALDI-TOF mass spectra of the abundant form of BSA found in normal whey and in mastitic whey $\left(\mathrm{M}_{\mathrm{r}} \approx 70 \mathrm{kDa}\right)$ differed slightly in terms of intensity of select ions and mass of tryptic peptides (Figure 4). The most notable difference in the peptide mass maps of bovine serum albumin isolated from normal and mastitic whey samples was the presence of a peptide with $m / z 1749$, which was unique to the spectrum of normal whey, and the presence a peptide with $m / z 1724$, which was apparent only in the spectrum from mastitic whey. Marked differences were apparent in the MALDI-TOF spectra of variant forms of serum albumin from mastitic whey samples, however (Figure 5), because the peptide with $\mathrm{m} / \mathrm{z}$ 1479, which exhibits a high intensity in intact serum albumin in both normal and mastitic whey, was absent from MS spectra of 2 of the serum albumin variants (spots 6 and 15). Additionally, clear differences existed in the size and distribution of tryptic peptides between the peptide mass maps of the variant forms of BSA. The peptide mass map of spot 6 was characterized by the high intensity of the peptide with $m / z 1511$, as well as a peptide with an $m / z 1166$ that was not present in any other forms of BSA. The results indicate potential modifications of BSA in the mastitic whey samples that resulted in variance among the peptide mass maps.

\section{a-1-Acid Glycoprotein is Present in Both Normal and Mastitic Whey Samples}

a-1-Acid glycoprotein was the only acute phase protein (APP) identified in both normal and mastitic whey samples. The $2 \mathrm{D}-\mathrm{GE}$ profiles of whey from milk collected from all of the cows in the study $(n=8)$ be-
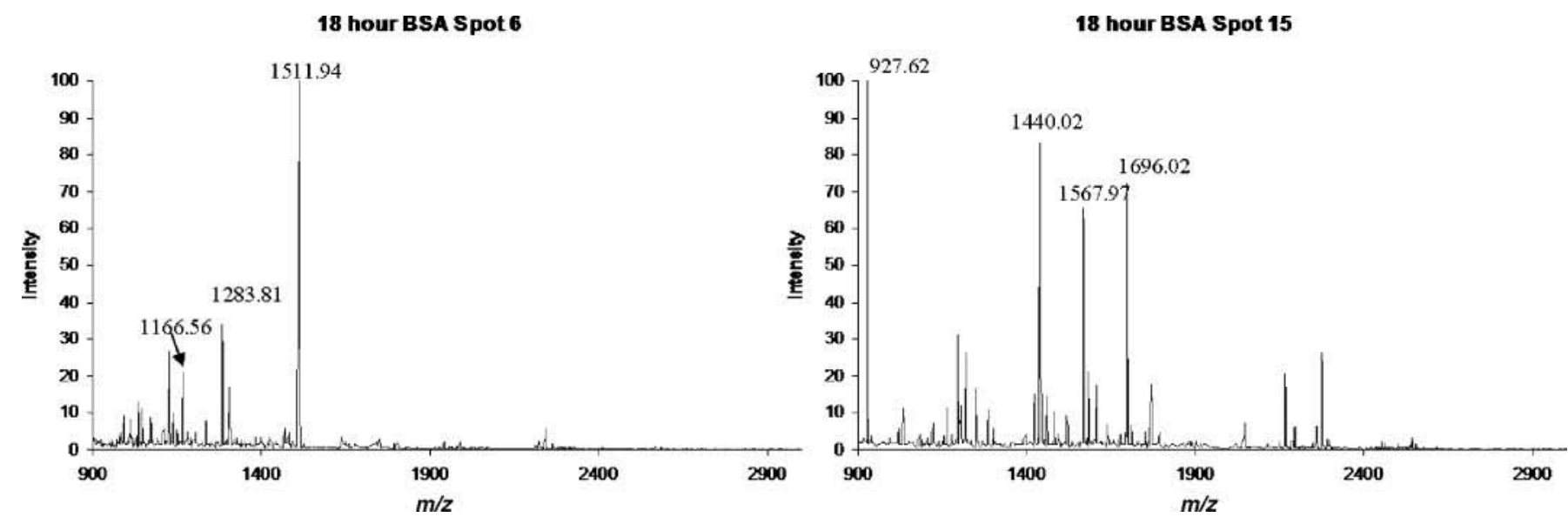

Figure 5. Mass spectra of variant forms of serum albumin in mastitic milk samples. Both spectra lack the abundant serum albumin peptide with $m / z 1479$. The spectra of spot 6 contains a peptide found only in that spot $(\mathrm{m} / z 1166)$, and the spectra of spot 15 contains a peptide $(m / z 1696)$ from complement C3. 
fore infection with $E$. coli revealed low abundance of a-1-acid glycoprotein. In contrast, 2D-GE of whey from milk collected $18 \mathrm{~h}$ after infection with $E$. coli revealed $\alpha$-1-acid glycoprotein to be in relatively high abundance. The identification of a-1-acid glycoprotein in whey from cows suffering from coliform mastitis has not been previously reported.

\section{DISCUSSION}

Results of the current study demonstrate that exposure to $E$. coli profoundly alters milk protein profiles. Additionally, the discovery of several low-abundance proteins not previously reported in proteomic analyses of bovine milk (Yamada et al., 2002; Hogarth et al., 2004; Smolenski et al., 2007) indicates the success of the current methods in identifying differentially expressed milk proteins during coliform mastitis.

In addition to the caseins $\alpha-\mathrm{S} 1, B$, and $\mathrm{x}$, the whey proteins B-lactoglobulin and a-lactalbumin, and polymeric immunoglobin receptor were all identified in these analyses as well as in previous proteomic analyses. Several other proteins were identified in whey samples from healthy cows, however, that were not reported in earlier proteomic investigations of normal milk (Yamada et al., 2002; Hogarth et al., 2004; Smolenski et al., 2007) including lactadherin, FABP, B-2 microglobulin, TTR, and epididymal secretory protein E1. Although lactadherin and FABP were found in the proteomic analysis of the milk fat globular membrane, neither of these proteins were identified in proteomic studies of normal whey. Lactadherin and FABP are known to be abundant in the milk fat globular membrane (Mather, 2000), and thus, it is reasonable to deduce that the identification of these proteins could be due to trace remnants of the fat layer present in the normal whey. Likewise, 6-2 microglobulin was identified in colostrum (Smolenski et al., 2007) but not in normal whey. Also identified in normal whey samples was epididymal secretory protein E1, also known as NPC2. Epididymal secretory protein $\mathrm{E} 1$ is a small lysosomal glycoprotein secreted in milk that is involved in cholesterol uptake (Xu et al., 2007). Epididymal secretory protein E1 has not been reported in previous investigations into the bovine milk proteome. The definitive presence of NPC2 in these normal whey samples is speculative, however, because only 1 peptide from the protein was successfully sequenced.

The presence of TTR in normal whey samples is compatible with previous proteomic analyses (Yamada et al., 2002; Hogarth et al., 2004; Smolenski et al., 2007); however, using the methods described in these analyses, TTR was identified in both the milk of healthy cows and in cows with coliform mastitis. Other proteins not previously identified in proteomic analyses of mastitic whey that were identified in the current study include the complement factors $\mathrm{C} 3$ and $\mathrm{C} 4$ and the apolipoproteins A-II and C-III. Complement C3 was previously identified in normal bovine whey (Yamada et al., 2002), but in the current study, complement C3 was identified in both normal and mastitic whey samples. These findings are compatible with the previously well-characterized role of the complement system in innate immunity (Rainard and Riollet, 2006). Although the discovery of complement factors in both normal and mastitic whey is not novel, the identification of these proteins using 2D-GE and MALDI-TOF PSD is supportive of the success of the methods used in the current study to identify low-abundance proteins without the prior sample clean-up. Additionally, apolipoprotein A-II and C-III were not found in previous proteomic analyses (Yamada et al., 2002; Hogarth et al., 2004; Smolenski et al., 2007). Apolipoprotein A-II is known synonymously as bovine AMP-1 and has been shown to have antimicrobial properties (Motizuki et al., 1998). The APP serum amyloid A (SAA) belongs to the apolipoprotein family, and SAA is known to be elevated during mastitis (Hirvonen et al., 1999; Eckersall et al., 2001; Grönlund et al., 2005). Whether or not the apolipoproteins identified in the current study are present in mastitic milk as the result of an acute phase response, leakage into the gland from systemic circulation, or the result of another mechanism entirely requires further analyses.

The appearance of serum albumin, serotransferrin, fibrinogen, fetuin (a-2-HS-glycoprotein), and $\alpha-1$ antiproteinase in relatively high abundance in the 2DGE of mastitic whey in the current proteomic analyses supports the leakage of serum proteins into milk after cytokine production and altered vascular permeability of the mammary epithelium. Serum albumin and serotransferrin have been identified previously in mastitic whey (Hogarth et al., 2004; Smolenski et al., 2007) as well as fibrinogen and fetuin (Smolenski et al., 2007); however, identification of a-1-antiproteinase in mastitic whey has not been reported.

The identification of several bovine AMP using MALDI-TOF-TOF PSD supports the influx of neutrophils into the mammary gland after $E$. coli invasion (Saad and Ostensson, 1990). The cytoplasmic granules of circulating neutrophils are a well-characterized source of AMP belonging to the cathelicidin family that are released upon neutrophil degranulation in the mammary gland (Tomasinsig and Zanetti, 2005). The identification of cyclic dodecapeptide (cathelicidin-1) in mastitic milk has been reported (Smolenski et al., 2007), but not indolicidin (cathelicidin-4), bactenecin-5 (cathelicidin-2), and bactenecin-7 (cathelicidin-3), as 
reported in the current study. Previous research on members of the cathelicidin family of host defense peptides has indicated that cathelicidins could function in the neutralization of endotoxin, as well as the downregulation of proinflammatory cytokine expression (Scott et al., 2002; Wiese et al., 2003; Zanetti, 2004). The identification of several members of the cathelicidin AMP in mastitic but not normal whey samples in these analyses supports the notion that AMP serve a role in host defense.

As in previous proteomic analyses comparing normal and mastitic bovine whey (Hogarth et al., 2004; Smolenski et al., 2007), serum albumin was detected in both normal and mastitic samples. However, in the current study, multiple forms of serum albumin were detected in mastitic whey. It is established that serum albumin levels increase dramatically in bovine milk during coliform mastitis, but there have not been previous reports of different isoforms of serum albumin in mastitic milk. Previous investigations have, however, demonstrated that albumin is synthesized and secreted by the bovine mammary gland and that local expression of albumin in the mammary gland was increased both in mastitic mammary tissue and after exposure to LPS when compared with expression in healthy mammary tissue (Shamay et al., 2005). Based on reported reverse transcription PCR data, the sizes of mammary-derived albumin and albumin in bovine serum appear to be the same (Shamay et al., 2005), but the exact amino acid sequence of the albumin expressed in the mammary gland was not determined. Differences in the peptide sizes, distribution, and relative intensities apparent in the MALDI-TOF spectra of tryptic fragments of albumin from normal and mastitic whey samples, as well as the variants of albumin detected in mastitic whey, could therefore have been due to potential structural differences between albumin produced in the mammary gland and albumin that leaked into the gland as a result of increased vascular permeability, but determination of such would require further investigation. Differences in the albumin MALDI spectra could also have been due to slight variance in conditions during the digestion stage, or the result of compounds bound to the serum albumin that might have affected tryptic digestion patterns. Serum albumin is known to bind and transport long-chain fatty acids as well as other small molecules including bradykinin and interferons, and acute phase proteins including SAA and $\alpha$-1-acid glycoprotein (Peters, 1977; Gundry et al., 2007). Bovine serum albumin is also known to have 3 isoforms with slightly differing isoelectric points (pI). In a previous study, bovine serum albumin exhibited the same molecular weight but 3 different $\mathrm{pI}(5.4,5.5$, and 5.6) after 2D-GE (Chang et al., 2005). Results of the current study, however, indicate shifts in both the size and the pI of BSA. The most likely explanation for the multiple forms of BSA apparent on the 2D gels of mastitic whey is proteolysis, which is consistent with previous findings that treatment with trypsin yielded several fragmented forms of BSA (Peters and Feldhoff, 1975). Fragments of BSA resulting from proteolysis did, however, retain the ability to bind ligands (Peters, 1977). Whether or not the obvious shift in mass and pI of the BSA fragments was in part due to binding of small molecules or proteins was not determined. In the current study, the majority of the peptides sequenced from spot 16 were serum albumin peptides. Evidence of the potential binding of other proteins to serum albumin was evident in this spot in mastitic whey, because one highly intense peptide that was present in the spectrum from spot 16 and subsequently sequenced $(\mathrm{m} / z$ 1696) matched complement C3. The explanation could be close proximity and therefore incomplete separation of the 2 proteins, or a binding event either before or after leakage into the mammary gland from systemic circulation.

Perhaps the most promising discovery in these proteomic analyses, however, was the identification of a-1-acid glycoprotein in both normal and mastitic whey samples and the apparent greater abundance of this APP in the mastitic samples. Previous analyses of APP expression during bovine mastitis have revealed increases in a-1-acid glycoprotein, SAA, LPS-binding protein, and haptoglobin levels in serum (Hirvonen et al., 1999; Bannerman et al., 2004; Hiss et al., 2004; Grönlund et al., 2005), but the only acute phase proteins to be identified in mastitic milk were SAA, LPS-binding protein, and haptoglobin (Eckersall et al., 2001; Bannerman et al., 2004; Hiss et al., 2004). A more recent study, however, identified a-1-acid glycoprotein in colostrum and normal milk of cattle (Ceciliani et al., 2005), and determined that $\alpha$-1-acid glycoprotein was expressed in mammary tissue. Likewise, there have been reports of the local expression of a-1-acid glycoprotein in human mammary epithelial cells (Gendler et al., 1982). The identification of a-1acid glycoprotein in normal whey is compatible with previous analyses (Ceciliani et al., 2005). The presence of a-1-acid glycoprotein in mastitic whey, however, has not been previously reported, but it is congruent with reports of increased hepatic production of APP during coliform mastitis and the subsequent leakage of APP into the milk as a result of altered vascular permeability (Eckersall et al., 2001; Bannerman et al., 2004; Hiss et al., 2004).

In the present study, 2D-GE performed on whey samples both before inoculation with $E$. coli and $18 \mathrm{~h}$ after infection revealed protein profiles with marked 
differences. A greater number of differentially expressed proteins in mastitic versus normal whey were identified than in previous analyses that utilized 2DGE followed by MS (Hogarth et al., 2004; Smolenski et al., 2007). The most likely explanation is that no sample clean-up steps were employed in the analyses reported here, which decreased protein loss and allowed for the identification of a greater number of proteins. The hypothesis regarding the number of proteins identified is supported by the success of a more recent proteomic analysis of several types of milk fractions (Smolenski et al., 2007) in identifying a greater number of milk proteins related to host defense despite the lack of sample clean-up before analysis. The number of cows sampled in the current study was much larger than previous analyses, and mastitis was experimentally induced so as to enable controlled analysis of changes in milk protein composition in response to infection. Both the larger sample size used and the experimental induction of mastitis improve the potential of the current study for discovering protein biomarkers while decreasing the risk of reporting a host defense response unique to only one or a small number of cows. Peptide identity scores are likewise an important parameter when considering the stringency of protein identification. Previous proteomic analyses failed to report scores associated with protein identification (Yamada et al., 2002; Smolenski et al., 2007), or the scores reported were based on peptide mass mapping (Hogarth et al., 2004). With few exceptions, the peptide identity scores reported in the current study are robust and the protein identification criteria more stringent. The methods and experimental design of the present study have demonstrated success in producing a more complete proteomic profile of milk protein changes during coliform mastitis, and have provided candidates for future research into the effects of $E$. coli-induced inflammation on protein expression in the bovine mammary gland.

\section{REFERENCES}

Bannerman, D. D., M. J. Paape, W. R. Hare, and E. J. Sohn. 2003. Increased levels of LPS-binding protein in bovine blood and milk following bacterial lipopolysaccharide challenge. J. Dairy Sci. 86:3128-3137.

Bannerman, D. D, M. J. Paape, J.-W. Lee, X. Zhao, J. C. Hope, and P. Rainard. 2004. Escherichia coli and Staphylococcus aureus elicit differential innate immune responses following intramammary infection. Clin. Diagn. Lab. Immunol. 11:463-472.

Ceciliani, F., V. Pocacqua, E. Provasi, C. Comunian, A. Bertolini, V. Bronzo, P. Moroni, and P. Sartorelli. 2005. Identification of the bovine a-1-acid glycoprotein in colostrum and milk. Vet. Res. 36:735-746.

Chang, W. W. P., C. Hobson, D. C. Bomberger, and L. V. Schneider. 2005. Rapid separation of protein isoforms by capillary zone electrophoresis with new dynamic coatings. Electrophoresis 26:2179-2186.
Eberhart, R. J., R. J. Harmon, D. E. Jasper, R. P. Natzke, S. C. Nickerson, J. K. Reneau, E. H. Row, K. L. Smith, and S. B. Spencer. 1987. Current Concepts of Bovine Mastitis. 3rd ed. National Mastitis Council Inc., Arlington, VA.

Eckersall, P. D., F. J. Young, C. McComb, C. J. Hogarth, S. Safi, A. Weber, T. McDonald, A. M. Nolan, and J. L. Fitzpatrick. 2001. Acute phase proteins in serum and milk from dairy cows with clinical mastitis. Vet. Res. 148:35-41.

Gendler, S. J., G. B. Dermer, L. M. Silverman, and Z. A. Tökés. 1982 Synthesis of a 1-antichymotrypsin and a 1-acid glycoprotein by human breast epithelial cells. Cancer Res. 42:4567-4573.

Grönlund, U., C. Hallén Sandgren, and K. Persson Waller. 2005. Haptoglobin and serum amyloid A in milk from dairy cows with chronic sub-clinical mastitis. Vet. Res. 36:191-198.

Gundry, R. L., Q. Fu, C. A. Jelinek, J. E. Van Eyk, and R. J. Cotter. 2007. Investigation of an albumin-enriched fraction of human serum and its albuminome. Proteomics Clin. Appl. 1:73-88.

Hirvonen, J., K. Eklund, A. M. Teppo, G. Huszenicza, M. Kulcsar, H. Saloniemi, and S. Pyörälä. 1999. Acute phase response in dairy cows with experimentally induced Escherichia coli mastitis. Acta Vet. Scand. 40:35-46.

Hiss, S., M. Mielenz, R. M. Bruckmaier, and H. Sauerwein. 2004 Haptoglobin concentrations in blood and milk after endotoxin challenge and quantification of mammary $\mathrm{Hp}$ mRNA expression. J. Dairy Sci. 87:3778-3784.

Hogan, J. S., W. P. Weiss, D. A. Todhunter, K. L. Smith, and P. S. Schoenberger. 1992. Efficacy of an Escherichia coli J5 mastitis vaccine in an experimental challenge trial. J. Dairy Sci. 75:415422.

Hogarth, C. J., J. L. Fitzpatrick, A. M. Nolan, F. J. Young, A. Pitt, and P. D. Eckersall. 2004. Differential protein composition of bovine whey: A comparison of whey from healthy animals and from those with clinical mastitis. Proteomics 4:2094-2100.

Konuma, T., K. Sakurai, and Y. Goto. 2007. Promiscuous binding of ligands by B-lactoglobulin involves hydrophobic interactions and plasticity. J. Mol. Biol. 368:209-218.

Lee, J.-W., D. D. Bannerman, M. J. Paape, M.-K. Huang, and X. Zhao. 2006. Characterization of cytokine expression in milk somatic cells during intramammary infections with Escherichia coli or Staphylococcus aureus by real-time PCR. Vet. Res. 37:219-229.

Lee, J.-W., M. J. Paape, T. H. Elsasser, and X. Zhao. 2003. Elevated milk soluble CD14 in bovine mammary glands challenged with Escherichia coli lipopolysaccharide. J. Dairy Sci. 86:23822389.

Mather, I. 2000. A review and proposed nomenclature for major proteins of the milk fat globule membrane. J. Dairy Sci. 83:203247.

McClenahan, D. J., J. P. Sotos, and C. J. Czuprynski. 2005. Cytokine response of bovine mammary gland epithelial cells to Escherichia coli, coliform culture filtrate, or lipopolysaccharide. Am. J. Vet. Res. 66:1590-1596.

Motizuki, M., T. Itoh, M. Yamada, S. Shimamura, and K. Tsurugi. 1998. Purification, primary structure, and antimicrobial activities of bovine apolipoprotein A-II. J. Biochem. 123:675-679.

Pareek, R., O. Wellnitz, R. Van Dorp, J. Burton, and D. Kerr. 2005. Immunorelevant gene expression in LPS-challenged bovine mammary epithelial cells. J. Appl. Genet. 46:171-177.

Peters, T. Jr. 1977. Serum albumin: Recent progress in the understanding of its structure and biosynthesis. Clin. Chem. 23:5-12.

Peters, T. Jr, and R. C. Feldhoff. 1975. Fragments of bovine serum albumin produced by limited proteolysis. Isolation and characterization of tryptic fragments. Biochemistry 14:33843391.

Rainard, P., and C. Riollet. 2006. Innate immunity of the bovine mammary gland. Vet. Res. 37:369-400.

Saad, A. M., and K. Ostensson. 1990. Flow cytofluorometric studies on the alteration of leukocyte populations in blood and milk during endotoxin-induced mastitis in cows. Am. J. Vet. Res. 51:1603-1607. 
Schepers, J. A., and A. A. Dijkhuizen. 1991. The economics of mastitis and mastitis control in dairy cattle: A critical analysis of estimates published since 1970. Prev. Vet. Med. 10:213-224.

Scott, M. G., D. J. Davidson, M. R. Gold, D. Bowdish, and R. E. Hancock. 2002. The human antimicrobial peptide LL-37 is a multifunctional modulator of innate immune responses. J. Immunol. 169:3883-3891.

Shamay, A., R. Homans, Y. Fuerman, I. Levin, H. Barash, N. Silanikove, and S. J. Mabjeesh. 2005. Expression of albumin in nonhepatic tissues and its synthesis by the bovine mammary gland. J. Dairy Sci. 88:569-576.

Shim, E. H., R. D. Shanks, and D. E. Morin. 2004. Milk loss and treatment costs associated with two treatment protocols for clinical mastitis in dairy cows. J. Dairy Sci. 87:2702-2708.

Shuster, D. E., M. E. Kehrli, and M. G. Stevens. 1993. Cytokine production during endotoxin-induced mastitis in lactating dairy cows. Am. J. Vet. Res. 54:80-85.

Smolenski, G., S. Haines, Y.-S. Kwan, F. Bond, J. Farr, V. Davis Sr., K. Stelwagen, and T. T. Wheeler. 2007. Characterization of host defense proteins in milk using a proteomic approach. J Proteome Res. 6:207-215.

Tomasinsig, L., and M. Zanetti. 2005. The cathelicidins - Structure, function and evolution. Curr. Protein Pept. Sci. 6:23-34.

Wiese, A., T. Gutsmann, and U. Seydel. 2003. Towards antibacterial strategies: Studies on the mechanisms of interaction between antibacterial peptides and model membranes. J. Endotoxin Res. 9:67-84

Xu, S., B. Benoff, H. L. Liou, P. Lobel, and A. M. Stock. 2007. Structural basis of sterol binding by NPC2, a lysosomal protein deficient in Niemann-Pick type C2 disease. J. Biol. Chem. 282:23525-23531.

Yamada, M., K. Murakami, J. Wallingford, and Y. Yuki. 2002 Identification of low-abundance proteins of bovine colostral and mature milk using two-dimensional electrophoresis followed by microsequencing and mass spectrometry. Electrophoresis 23:1153-1160.

Zanetti, M. 2004. Cathelicidins, multifunctional peptides of the innate immunity. J. Leukoc. Biol. 75:39-48. 